\title{
Multiply charged energetic metal ion emissions from dinuclear metal complex exposed to intense femtosecond laser fields
}

Takuya Matsumoto, Hiroki Tanaka, Nobuaki Nakashima, Tomoyuki Yatsuhashi

\begin{tabular}{|c|l|}
\hline Citation & International Journal of Mass Spectrometry. 447; 116236 \\
\hline Issue Date & $2020-01$ \\
\hline Type & Journal Article \\
\hline Textversion & author \\
\hline \multirow{3}{*}{ Rights } & $\begin{array}{l}\text { C } 2019 \text { Elsevier B.V. This manuscript version is made available under the } \\
\text { CC-BY-NC-ND 4.0 License. http://creativecommons.org/licenses/by-nc-nd/4.0/. } \\
\text { The following article has been accepted by International Journal of Mass } \\
\text { Spectrometry. The article has been published in final form at } \\
\text { https://doi.org/10.1016/j.ijms.2019.116236. }\end{array}$ \\
\hline DOI & $10.1016 /$ j.ijms.2019.116236 \\
\hline
\end{tabular}

\author{
Self-Archiving by Author(s) \\ Placed on: Osaka City University Repository
}




\title{
Multiply charged energetic metal ion emissions from dinuclear metal complex exposed to intense femtosecond laser fields
}

Takuya Matsumoto, Hiroki Tanaka, Nobuaki Nakashima, Tomoyuki Yatsuhashi

\begin{tabular}{|c|l|}
\hline Citation & International Journal of Mass Spectrometry. 447; 116236 \\
\hline Issue Date & $2020-01$ \\
\hline Type & Journal Article \\
\hline Textversion & author \\
\hline \multirow{3}{*}{ Rights } & $\begin{array}{l}\text { C } 2019 \text { Elsevier B.V. This manuscript version is made available under the } \\
\text { CC-BY-NC-ND 4.0 License. http://creativecommons.org/licenses/by-nc-nd/4.0/. } \\
\text { The following article has been accepted by International Journal of Mass } \\
\text { Spectrometry. The article has been published in final form at } \\
\text { https://doi.org/10.1016/j.ijms.2019.116236. }\end{array}$ \\
\hline DOI & $10.1016 /$ j.ijms.2019.116236 \\
\hline
\end{tabular}

\author{
Self-Archiving by Author(s) \\ Placed on: Osaka City University Repository
}

MATSUMOTO, T., TANAKA, H., NAKASHIMA, N., \& YATSUHASHI, T. (2020). Multiply charged energetic metal ion emissions from dinuclear metal complex exposed to intense femtosecond laser fields. International Journal of Mass Spectrometry. 447. DOI: 10.1016/j.ijms.2019.116236 


\section{Multiply charged energetic metal ion emissions}

\section{from dinuclear metal complex exposed to intense}

\section{femtosecond laser fields}

Takuya Matsumoto,,$^{\dagger}$ Hiroki Tanaka,,$^{\dagger}$ Nobuaki Nakashima, Tomoyuki Yatsuhashi*

Department of Chemistry, Graduate School of Science, Osaka City University, 3-3-138

Sugimoto, Sumiyoshi-ku, Osaka 558-8585 Japan

$\uparrow$ These authors contributed equally to this work.

Keywords: Coulomb explosion; Manganese ion; Time-of-flight mass spectroscopy

* Corresponding author at: Department of Chemistry, Graduate School of Science, Osaka City University, 3-3-138 Sugimoto, Sumiyoshi-ku, Osaka 558-8585, Japan. Tel.:+81 66605 2554

E-mail address: tomo@sci.osaka-cu.ac.jp (T. Yatsuhashi) 

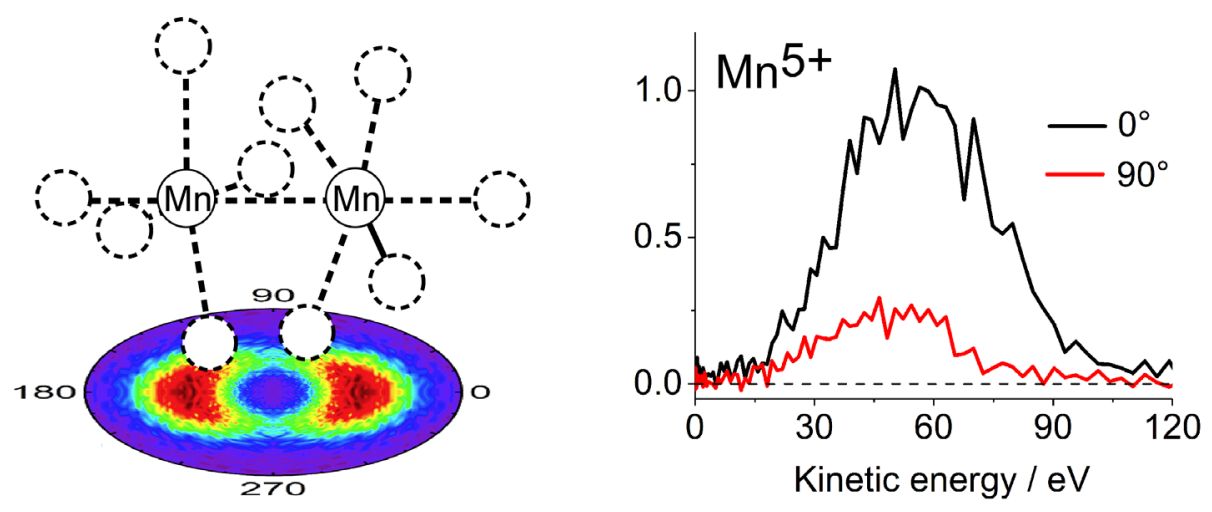

Graphical Abstract 


\section{ABSTRACT}

Coulomb explosion of nonmetal ions emerged from a variety of molecules has been studied and utilized for the determination of molecular structure and reaction dynamics. In contrast, Coulomb explosion of metal ions, particularly the large Coulombic interactions are expected, has not yet been explored. In this study, the angular distributions of $\mathrm{Mn}^{x+}(x=1-5), \mathrm{C}^{{ }^{+}}(y=$ $1-4)$, and $\mathrm{O}^{z+}(z=1-3)$ emerged from dimanganese decacarbonyl, in which two metal atoms are sandwiched by axial ligands, exposed to intense femtosecond laser fields $\left(1 \times 10^{14}-3 \times 10^{15}\right.$ $\mathrm{W} \mathrm{cm}^{-2}$ ) are investigated. Manganese ions are produced at relatively low laser intensity compared with other transition metal ions with the same charge number but emerged from mononuclear complexes such as metallocenes and metal hexacarbonyls. The kinetic energies of $\mathrm{Mn}^{4+}$ and $\mathrm{Mn}^{5+}$ are described by the simple Coulomb repulsion model of manganese dimer ion. Fairly high kinetic energy of oxygen and carbon ions compared with those emerged from metal hexacarbonyls strongly suggests that atomic ions originating in ligands are repelled by manganese ions at the moment of Coulomb explosion. The use of dinuclear metal complex is advantageous in the production of multiply charged metal ions accompanying high kinetic energy since two manganese ions are in close confinement due to the repulsions with axial ligand (atomic) ions. 


\section{Introduction}

Multiply charged atomic ion emission is one of the characteristic phenomena of molecules exposed to intense laser fields.[1] The origin of such ions accompanying high kinetic energy is the Coulomb explosion of multiply charged species formed by the sequential tunnel ionization.[2] Tracing the history of the ion emission studies in intense femtosecond laser fields, the most examined atomic ions emerged from organic molecules have been hydrogen, second low elements $(\mathrm{C}, \mathrm{N}, \mathrm{O})$, and halogens $(\mathrm{F}, \mathrm{Cl}, \mathrm{Br}, \mathrm{I}) \cdot[3,4]$ The angular distribution and kinetic energy of nonmetal ions that are subject to the interactions among other nonmetal ions, have been discussed in terms of molecular structure and its deformation in intense laser fields.[5] The emissions of hydrogen and halogen ions that are originally connected with other atom by a single bond are straightforward and have been utilized for structural determination by Coulomb explosion imaging.[6] In contrast, the emissions of charged carbon, oxygen, nitrogen, and silicon atoms, which are part of molecular skeleton, are complicated because they are ejected after the interactions with surrounding ions. In the cases of three- and four-atom molecules such as $\mathrm{CS}_{2},[7-9] \mathrm{CO}_{2},[5]$ OCS,[10] $\mathrm{H}_{2} \mathrm{CO},[11]$ and $\mathrm{C}_{2} \mathrm{I}_{2}$ [12]; however, these interactions can give fruitful information about the molecular deformation in intense laser fields. In the cases of acetylene derivatives, the carbon ions are ejected parallel $\left(\mathrm{C}_{2} \mathrm{H}_{2}\right)$ or perpendicular $\left(\mathrm{C}_{2} \mathrm{I}_{2}\right)$ with respect to the molecular axis. [12] These emission behaviors might be extreme cases since the mass of hydrogen and iodine atoms are more than ten times smaller or larger than that of carbon atom, respectively. It is interesting to prepare the moderate situation that target atoms are sandwiched by the atoms (substituents) with equivalent mass. We emphasize that such situation can be found in the emission of charged metals that are part of molecular skeleton of organometallic compounds. In addition, investigations of the ionization behavior of metal atoms that have rarely been reported are 
important for a further step toward understanding the ionization of many-electron systems in intense laser fields.[13, 14]

As for the production of metal ions in intense laser fields, pure metals, [13-15] metal compounds,[16-24] and organometallic molecules[25-28] can be used as the metal ion source. Stolow and coworkers presented the production of singly charged transition metals such as V, $\mathrm{Nb}, \mathrm{Ta}, \mathrm{Ni}, \mathrm{Pd},[13,14]$ and Ni cluster ions[14] by femtosecond laser pulses. In their experiments, neutral metals seeded by the laser ablation of a metal rod with nanosecond laser pulses were exposed to intense femtosecond laser pulses. The ionization of metal,[15] metal oxide,[16-22] and metal carbide[18, 23, 24] clusters in intense femtosecond laser field was vigorously studied by Castleman and coworkers. At the same time, the productions of multiply charged metals as well as their large kinetic energy release in clusters have also been reported by using nanosecond laser pulses.[29, 30] Several ionization and relaxation mechanisms in clusters have been proposed, and controversy as to arguments regarding the energy gain mechanism is ongoing.[31-33] Kinetic energy of ions formed in clusters is not simply explained by the interaction between ions but by the collective effect of many atoms, atomic ions, and electrons. Therefore, a neutral metal dimer, which can be produced by using a cluster source, is the best candidate to investigate the Coulomb interaction between metal ions. The selection of singly charged metal dimer is possible; however; that of neutral species is hardly possible. Herein, we suggest to use a dinuclear metal complex to observe Coulomb repulsion interaction between metal ions. In this study, the Coulomb explosion of dimanganese decacarbonyl, $\mathrm{Mn}_{2}(\mathrm{CO})_{10}$, which is one of the simplest binuclear carbonyl complexes having near- $D_{4 \mathrm{~d}}$ symmetry, where the oxidation number of manganese is zero and the $\mathrm{CO}$ is neutral ligand, is investigated in high intensity femtosecond laser fields. 


\section{Materials and methods}

Dimanganese decacarbonyl $\left(\mathrm{Mn}_{2}(\mathrm{CO})_{10}\right.$, Acros Organics, 98.0\%) and xenon (Japan Air Gases, $99.99 \%$ ) were used without further purification. $\mathrm{Mn}_{2}(\mathrm{CO})_{10}$ and xenon was introduced effusively by a leak valve. The pressure of $\mathrm{Mn}_{2}(\mathrm{CO})_{10}$ was maintained at $7.5 \times 10^{-5} \mathrm{~Pa}$. The experimental details have been described elsewhere.[34] Briefly, multiple ionization was carried out with a $40-\mathrm{fs}$ pulse centered at $0.8 \mu \mathrm{m}$ delivered from a $1-\mathrm{kHz}$-repetition-rate Ti:Sapphire laser (Alpha 100/1000/XS hybrid, Thales Laser), and the ions were detected by a liner mode of Wiley-McLaren time-of-flight mass spectrometer (KNTOF-1800, TOYAMA). The actual laser intensity of the linear polarized pulse at the focus was determined by measuring the saturation intensity of xenon $\left(1.1 \times 10^{14} \mathrm{~W} \mathrm{~cm}^{-2}\right.$ for a $45 \mathrm{fs}$ pulse $)$ by the method of Hankin et al. $[35,36]$, and the error in the determination of absolute laser intensity was about $\pm 10 \%$. The ions of the $\mathrm{Mn}_{2}(\mathrm{CO})_{10}$ were measured successively after the measurement of the saturation intensity of xenon without, between two runs, changing experimental conditions. The time-of-flight spectra obtained by averaging 1000 laser shots were used to evaluate kinetic energy as described elsewhere.[37] The atomic ion yields were obtained by integrating over the corresponding peaks of time-of-flight spectrum. Here we defined the angle $\theta$ that was measured with respect to the polarization plane of the laser fields from the ion flight axis to the detector. When the direction of laser polarization is parallel $(\theta$ $\left.=0^{\circ}, 180^{\circ}\right)$ or perpendicular $\left(\theta=90^{\circ}, 270^{\circ}\right)$ to the ion flight axis, it is referred to as "parallel" or "orthogonal," respectively. The kinetic energy spectra were measured for the two quadrants with 4-degree steps experimentally, and these data were averaged to improve the ratio of signal intensity to noise intensity, since the two quadrants were almost identical. A polar plot of angular distribution of ions was generated from the averaged data to present the information more clearly. 


\section{Results and discussion}

\subsection{Ionization and fragmentation of $\mathrm{Mn}_{2}(\mathrm{CO})_{10}$}

The time-of-flight spectra of $\mathrm{Mn}_{2}(\mathrm{CO})_{10}$ measured at $3.2 \times 10^{15}, 7.0 \times 10^{14}$, and $9.7 \times 10^{13} \mathrm{~W}$ $\mathrm{cm}^{-2}$ are shown in Fig. 1. At the highest laser intensity, the atomic ions such as $\operatorname{Mn}^{x+}(x=1-$ 5), $\mathrm{C}^{y^{+}}(y=1-4)$, and $\mathrm{O}^{z+}(z=1-3)$ dominated the mass spectra. The multiply charged molecular cation[38-41] was absent, but we detected $\mathrm{Mn}_{2}(\mathrm{CO})_{10}{ }^{+}$and some fragment ions such as $\mathrm{Mn}_{2}(\mathrm{CO})_{m}{ }^{+}(m=0-7), \mathrm{Mn}(\mathrm{CO})_{n}{ }^{+}(n=1-5), \mathrm{MnC}^{+}, \mathrm{Mn}(\mathrm{CO})^{2+}$, and $\mathrm{CO}^{+}$. The COloss reactions without metal-metal bond cleavage and/or metal-metal bond cleavage without breaking metal- $\mathrm{CO}$ bonds are interesting in connection with photochemistry $[42,43]$ and theoretical chemistry[44] of $\mathrm{Mn}_{2}(\mathrm{CO})_{10}$; however, we will, in this study, focus on the multiply charged manganese, carbon, and oxygen ions originated from the Coulomb explosion of highly charged precursor ion. $\mathrm{Mn}^{+}$was detected as a single broad peak in the time-of-flight spectrum, whereas other atomic ions appeared as multiple peaks. The origin of the broad and/ or multiple peaks is the kinetic energy of atomic ions produced by Coulomb explosion.[37] Since the ions with certain kinetic energy are emitted forward and backward along the ion flight axis determined by the applied static electric field in the acceleration region of time-of-flight mass spectrometer, those ions are detected with a certain time delay in the time-of-flight spectrum. It should be mentioned that the peak of $\mathrm{Mn}^{2+}(\mathrm{m} / z$ 27.5) emitted in backward direction was overlapped with that of $\mathrm{CO}^{+}(m / z 28)$. Further, the $\mathrm{Mn}^{3+}$ peak $\left(m / z\right.$ 18.3) emitted in forward direction was overlapped with that of $\mathrm{H}_{2} \mathrm{O}^{+}(m / z 18.0)$. The peaks of other atomic ions were not interfered with the adjacent peaks.

Here we compare the mass spectra of $\mathrm{Mn}_{2}(\mathrm{CO})_{10}$ with those of other metal complexes. In the cases of metallocenes (mononuclear metal complexes), most cyclopentadienyl ligands are detached as neutral fragments, and the amounts of carbon-containing fragment ions are very 
small relative to those of metal ions.[27, 28] We have proposed that metal ions having higher charges are formed by the sequential (stepwise) tunnel ionization of the singly (doubly) charged metal ions that are liberated from the excited metallocene ions. In the cases of metal hexacarbonyls (mononuclear metal complexes), we have concluded that CO ligands are highly charged and close to a metal ion at the moment of Coulomb explosion because the kinetic energy of carbon ions originating from ligands is strongly affected by the central metal charge: more highly charged metal has higher Coulomb repulsion energy.[26] The mass spectra of $\mathrm{Mn}_{2}(\mathrm{CO})_{10}$ was dominated by atomic ions, i.e. almost complete atomization was achieved. This evidence indicates that $\mathrm{CO}$ ligands in $\mathrm{Mn}_{2}(\mathrm{CO})_{10}$ are highly charged followed by Coulomb explosion as in the cases of metal hexacarbonyls.

\subsection{Saturation intensities of metal ions}

Fig. 2 shows the atomic ion yields as a function of laser intensity. The ion yields increased very steeply as laser intensity increased until it reached the saturation region. Here, we compare the saturation intensity, which is the index of ionization rate, $[35,36]$ of manganese ions with those of other transition metal ions emerged from mononuclear complexes. Saturation intensity is defined as the point at which the ion yield (linear scale), extrapolated from the high-intensity linear portion of the curve, intersects the intensity axis (logarithmic scale). Saturation intensities of $\mathrm{Mn}^{x+}$ were $3.0 \times 10^{13}(x=1), 9.8 \times 10^{13}(x=2), 17 \times 10^{13}(x=3)$, $33 \times 10^{13}(x=4)$, and $69 \times 10^{13} \mathrm{~W} \mathrm{~cm}^{-2}(x=5)$, respectively. Fig. 3 shows the saturation intensity of metal ions as a function of the ionization energy of metal atoms. It is noted that ionization energy is the energy required to remove an electron from an atom with the subsequent production of a positively charged ion. Since the saturated neutral mononuclear manganese complex is not available, we compared the saturation intensities of $\mathrm{Mn}^{x+}$ with those of transition metal ions (Cr, Mo, W) emerged from metal hexacarbonyls (Fig. 3, 
left).[26] In addition, the data of chromium, iron, and nickel ions ejected from the corresponding metallocenes were compared with those of manganese ions emerged from $\mathrm{Mn}_{2}(\mathrm{CO})_{10}$ (Fig. 3, right). The saturation intensity of metal ion emerged from metal hexacarbonyls seems to depend on ionization energy regardless of the elements. This is also true for the metal ions of fourth-row elements ejected from metallocenes. Strictly speaking; however, such comparison is not valid for the metal ions ejected from organometallic complexes but only meaningful for the metal ions generated from isolated atoms. Nevertheless, we can state that the production of the metal ion with specific charge number from metal hexacarbonyls require higher laser intensity than metallocenes. Further, it is obvious that multiply charged manganese ions are produced at relatively low laser intensity compared with other metal ions with the same charge number originating from mononuclear complexes. Although the results are open to some interpretation, these features are not further examined in this study because we do not have information about other dinuclear complex. Anyway, these results lead us to emphasize that the production of metal ions from dinuclear complex in intense laser fields is very interesting subject for future experimental and theoretical investigations.

\subsection{Angular distribution of manganese ions}

We investigated the manganese ion emission behavior in details at three laser intensities: $9.7 \times 10^{13}, 7.0 \times 10^{14}$, and $3.2 \times 10^{15} \mathrm{~W} \mathrm{~cm}^{-2}$. Fig. 4 shows the angular distribution of manganese ions. The kinetic energy spectra measured under parallel and orthogonal conditions are shown in Fig. 5. The kinetic energies of manganese ions are listed in Table 1. Here, we defined the peak kinetic energy as the energy at peak ion intensity. In addition, the maximum kinetic energy was defined as the energy at $10 \%$ of the peak ion intensity. As clearly shown in Figs 4 and 5, manganese ions were predominantly emitted in parallel direction. In order to 
compare the anisotropic emission of ions in more quantitative manner, it is worth noting to compare the ratio, which we define as the "extinction" of ion, that is, of the ion intensity (peak value) measured under an orthogonal condition to that measured under a parallel condition.[26] If the extinction (orthogonal/parallel) is not unity, the emission of ions occurs in anisotropic manner with respect to laser polarization direction. The extinction of manganese ions varied from 0 to 1 depending on their charge number and laser intensity (Table 1). It is mentioned that metal ions emerged from metallocenes do not carry noticeable kinetic energy and thus the extinctions of them were unity because the most cyclopentadienyl ligands are liberated as neutral fragments.[27, 28] The extinctions of metal ions ejected from group 6 metal (Cr, Mo, W) hexacarbonyls were also unity.[26] This is mainly due to the fact that metal hexacarbonyls are mononuclear and highly symmetric $\left(O_{\mathrm{h}}\right)$ organometallic complexes, in which a metal is located in the center of gravity of complex. Therefore, a metal ion, which experiences identical Coulomb repulsive forces from the surrounding CO ligand ions, does not change its momentum by Coulomb explosion. Based on these previous findings, we conclude that the anisotropic emission of manganese ions is not due to the interactions with charged $\mathrm{CO}$ ligands but mainly to the repulsion with adjacent manganese ion. Of course, such interaction is expected for the molecules whose Mn-Mn axis is parallel to the laser polarization direction when they are ionized.

Fig. 6 shows the kinetic energies of $\mathrm{Mn}^{x+}(x=1-5)$ as a function of the charge number or the square of the charge number. It is noteworthy that the maximum kinetic energies were linearly proportional to the charge number, whereas the peak kinetic energies were linearly proportional to the square of the charge number. The shape of kinetic energy spectra of manganese ions was broad because the peak is the superposition of several peaks originating in Coulomb explosion of precursor ion with different charge numbers occurring at different interion distances. Therefore, in principle, we need to measure the coincidence or 
covariance to determine the charge numbers of the ion pair participating in Coulomb explosion.[7, 45] Nevertheless, the trends shown in Fig. 6 indicates that the peak kinetic energy of $\mathrm{Mn}^{x+}$ might reflect the Coulomb repulsion between $\mathrm{Mn}^{x+}$ and the manganese ions with the charge number equals to $x$, while the maximum kinetic energy could be the results of the Coulomb repulsion of $\mathrm{Mn}^{x+}$ and the rest of charges in the precursor ion.

In order to accurately simulate the kinetic energy of manganese ions, it is necessary to consider all possible combinations of charges on each atom over the molecule. However, such consideration is unrealistic for non-linear and non-symmetric molecule, $\operatorname{Mn}_{2}(\mathrm{CO})_{10}$ consisting of 22 atoms. In view of the production of multiply charged ion with high kinetic energy, we compare the kinetic energy of manganese ions emerged from $\mathrm{Mn}_{2}(\mathrm{CO})_{10}$ and that expected for manganese dimer ions. We calculated the kinetic energy of manganese ions ejected from a manganese dimer ion $\left(\mathrm{Mn}^{x+}-\mathrm{Mn}^{x^{\prime}+}, x=1-5, x^{\prime}=1-5\right)$ simply by assuming pure Coulomb interactions between point charges. Supposing that the distance between manganese ions at the moment of Coulomb explosion is $2.977 \AA$, which is the equilibrium internuclear distance between manganese atoms in $\mathrm{Mn}_{2}(\mathrm{CO})_{10 .}$ [46] According to the pioneering studies about the charge-symmetric and charge-asymmetric Coulomb explosion of diatomic molecules, the difference of the charge number in an ion pair is mostly $0, \pm 1$ and \pm 2 , respectively.[47] Therefore, we calculated the kinetic energy of $\mathrm{Mn}^{x+}$ ejected from $\mathrm{Mn}^{x+}-\mathrm{Mn}^{x^{\prime}+}\left(1 \leq x^{\prime} \leq 5, x^{\prime}=x, x \pm 1, x \pm 2\right)$. The evaluated values are shown in Fig. 5 . The kinetic energies evaluated for the dissociation path $\left(x^{\prime}=x \pm 2\right)$ were far from the experimentally obtained peak kinetic energies. Supposing that $x^{\prime}=x$, the peak kinetic energies were $53 \%\left(\mathrm{Mn}^{2+}\right), 76 \%\left(\mathrm{Mn}^{3+}\right), 91 \%\left(\mathrm{Mn}^{4+}\right)$, and $90 \%\left(\mathrm{Mn}^{5+}\right)$, respectively, relative to the calculated values. In the cases of $x^{\prime}=x+1$, the ratios were $35 \%\left(\mathrm{Mn}^{2+}\right), 57 \%\left(\mathrm{Mn}^{3+}\right)$, and $73 \%\left(\mathrm{Mn}^{4+}\right)$, respectively. Supposing that $x^{\prime}=x-1$, the ratios were $106 \%\left(\mathrm{Mn}^{2+}\right), 114 \%$ $\left(\mathrm{Mn}^{3+}\right), 121 \%\left(\mathrm{Mn}^{4+}\right)$, and $113 \%\left(\mathrm{Mn}^{5+}\right)$, respectively. Given the assumption that the 
Coulomb repulsion between $\mathrm{Mn}^{z+}$ and $\mathrm{Mn}^{z}{ }^{\text {,+ }}\left(z^{\prime}=z, z \pm 1\right)$ dominantly contributes to give the peak kinetic energy, the above-mentioned simple calculations fail to reproduce the peak kinetic energies of $\mathrm{Mn}^{+}, \mathrm{Mn}^{2+}$, and $\mathrm{Mn}^{3+}$. In contrast, the peak kinetic energy of $\mathrm{Mn}^{4+}$ and $\mathrm{Mn}^{5+}$ was described by the simple Coulomb repulsion model of manganese dimer ion. The latter results are unexpected because the reduction of kinetic energy has been observed in many molecules known as enhanced ionization: Coulomb explosion takes place at an elongated molecular geometry and thus the kinetic energy of ions is lower than those expected from the initial geometry.[48-50] In many cases, the enhanced ionization takes place at approximately twice the equilibrium internuclear distance in the neutral state that corresponds to $50 \%$ reduction of kinetic energy. In the case of iodine molecule; however, the reduction of kinetic energy compared with those calculated at equilibrium distance of neutral state varies from $87 \%\left(\mathrm{I}_{2}{ }^{2+}\right)$ to $72 \%\left(\mathrm{I}_{2}{ }^{13+}\right)$.[47] Though the degree of kinetic energy reduction, hence the degree of bond elongation depends on the mass of atoms, enhanced ionization picture should be reasonable for a manganese dimer ion, if it exists, since the separation of ions is not disturbed at all. Therefore, the kinetic energy of $\mathrm{Mn}^{4+}$ and $\mathrm{Mn}^{5+}$ emerged from $\mathrm{Mn}_{2}(\mathrm{CO})_{10}$ might be unusually high presumably due to the presence of ligands in the axial position.

The pioneering work of Coulomb explosion of acetylene showed that the C-C bond elongation was not disturbed by the presence of terminal hydrogen atoms, and the experimentally observed kinetic energy of carbon ions compared with those calculated at the equilibrium distance of singly charged acetylene was 53\% regardless of the dissociation channels.[51] Contrary to the diatomic molecules and a four-atom molecule with light terminal atoms, the manganese ion in $\mathrm{Mn}_{2}(\mathrm{CO})_{10}$ experiences Coulomb repulsive forces from both adjacent manganese ion and charged ligands with relatively large mass and high charge number compared with proton. The kinetic energy of manganese ions would be determined 
by several parameters such as the charge of ligands (carbon and oxygen ions) and manganese ions, the distance between manganese ions, and the distance between manganese ion and charged ligands. Therefore, we next consider the kinetic energy of oxygen and carbon ions.

\subsection{Angular distribution of oxygen and carbon ions}

Fig. 7 shows the angular distribution of carbon and oxygen ions measured at $3.2 \times 10^{15} \mathrm{~W}$ $\mathrm{cm}^{-2}$. The kinetic energy spectra measured under parallel and orthogonal conditions at $3.2 \times 10^{15} \mathrm{~W} \mathrm{~cm}^{-2}$ are shown in Fig. 8. The kinetic energies and the extinction of carbon and oxygen ions are listed in Table 2. The data of $\mathrm{Cr}(\mathrm{CO})_{6}$, in which $\mathrm{Cr}$ has the relative atomic mass (51.9) similar to that of Mn (54.9), are also shown in Table 2 as references. In both $\mathrm{Cr}(\mathrm{CO})_{6}$ and $\mathrm{Mn}_{2}(\mathrm{CO})_{10}$, the emission of oxygen ions would reflect the molecular structure because oxygen atoms are located on the edge of the molecule, and thus the emission of oxygen ions is not obstructed at all. In the cases of metal hexacarbonyls with $O_{\mathrm{h}}$ symmetry, we have explained the emission of carbon and oxygen ions in terms of the geometric alignment and the most probable electron extraction axes.[26] These assumptions lead us to explain why the extinctions of $\mathrm{O}^{+}$and $\mathrm{O}^{2+}$ are close to 0.5 . In contrast to the metal hexacarbonyls, the extinctions of oxygen ions $\left(\mathrm{O}^{+}, \mathrm{O}^{2+}\right)$ ejected from $\mathrm{Mn}_{2}(\mathrm{CO})_{10}$ were fairly large. The large extinctions of oxygen ions are attributed to a variety of ligand configurations in $\mathrm{Mn}_{2}(\mathrm{CO})_{10}$. The structure of neutral $\mathrm{Mn}_{2}(\mathrm{CO})_{10}$ in gas phase is near-staggered form (near$D_{4 d}$ symmetry),[52] where each manganese atom has a pseudo-octahedral coordination, i.e. four $\mathrm{CO}$ ligands in equatorial positions, and a $\mathrm{CO}$ ligand and another manganese atom in axial positions. Therefore, the consideration for the emission of oxygen ions from metal hexacarbonyls with $O_{\mathrm{h}}$ symmetry is not simply applicable to $\mathrm{Mn}_{2}(\mathrm{CO})_{10}$.

In contrast to the kinetic energy spectra of manganese ions, those of carbon and oxygen ions showed several peaks (Fig. 8). We can recognize sharp distinct peak(s) in the 
low energy region in addition to a broad peak in the high energy region. The extinction of sharp $\mathrm{C}^{+}$and $\mathrm{O}^{+}$peaks are difficult to determine due to the overlap with a broad peak. In contrast, it is obvious that the extinction of sharp $\mathrm{C}^{y+}(y=2-4)$ and $\mathrm{O}^{z+}(z=2-4)$ peaks were zero. Based on the kinetic energy and extinction, we conclude that the origin of the sharp peaks is the Coulomb explosion of the liberated neutral $\mathrm{CO}$ as in the cases of metal hexacarbonyls.[26] The liberated neutral CO may be ionized by the subsequent laser pulses since neutral molecules can stay in the ionization volume for a sufficient duration.[26] Both peak and maximum kinetic energies of broad carbon and oxygen ion peaks (except for the peak kinetic energy of $\mathrm{C}^{+}$) were more than 1.5 times higher than that ejected from $\mathrm{Cr}(\mathrm{CO})_{6}$ (Table 2). The origin of the high kinetic energy of carbon and oxygen ions should be the Coulomb repulsion with adjacent highly charged manganese ions. Therefore, ionized ligands are expected to stay close to both manganese ions to earn large Coulomb repulsive force, i.e. both ligand-Mn and Mn-Mn distances are not significantly elongated, at the moment of Coulomb explosion of ligand ions. At present, definitive conclusion cannot be made, but we propose that both axial CO ligand (atomic) ions repel manganese ions and suppress the elongation of Mn-Mn distance until manganese ions explode. Moreover, this effect would be significant as the manganese ions and $\mathrm{CO}$ ligands are more highly charged.

\section{Conclusion}

In this study, the interaction between metal ions is investigated by preparing a pair of multiply charged manganese ions in $\mathrm{Mn}_{2}(\mathrm{CO})_{10}$. We emphasize that the use of a dinuclear metal complex for the production of metal ions has specific features. 1) Metal ions are ejected at relatively low laser intensity compared with other metal ions emerged from mononuclear metal complexes. For further investigations, it is preferable to examine the similar homo dinuclear metal complexes but having different mass and electron configuration of metals, for 
example, $\operatorname{Re}_{2}(\mathrm{CO})_{10}$. Moreover, hetero dinuclear metal complex and/or multinuclear metal complex such as $\mathrm{Ru}_{3}(\mathrm{CO})_{12}$ are promising candidates to be investigated. 2) The kinetic energy of manganese ions $\left(\mathrm{Mn}^{4+}, \mathrm{Mn}^{5+}\right)$ is similar to that calculated for manganese dimer ion. This suggests that the effect of ligand ions on the kinetic energy of manganese ions is minimal in total due to the high symmetry of ligand configuration. We speculate that two manganese ions are confined in space due to the repulsion with ligand (atomic) ions at the moment of Coulomb explosion. 3) Fairly high (almost twice) kinetic energy of oxygen and carbon ions compared with those emerged from mononuclear complex is obtained due to the repulsion with manganese ions.

\section{Acknowledgments}

The present research was partially supported by JST PRESTO program and JSPS KAKENHI Grant Number JP26107002 in Scientific Research on Innovative Areas "Photosynergetics." 
(a)

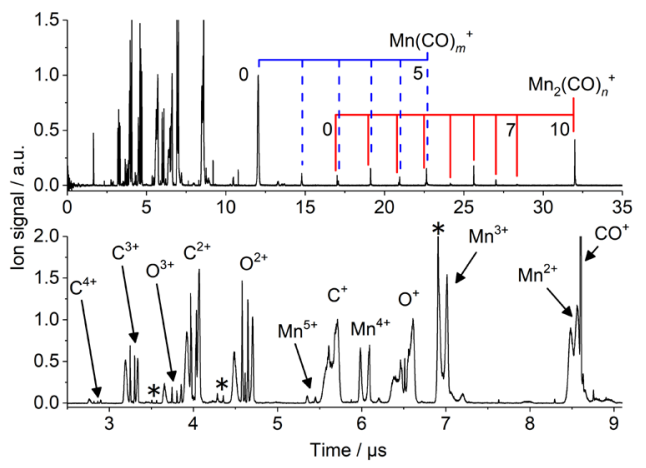

(b)

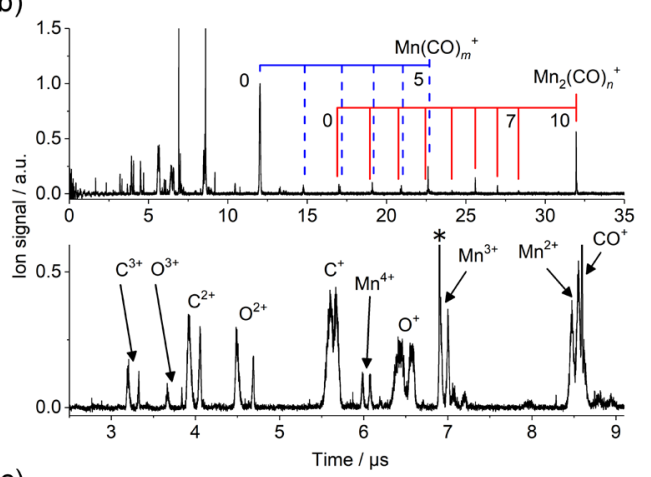

(c)

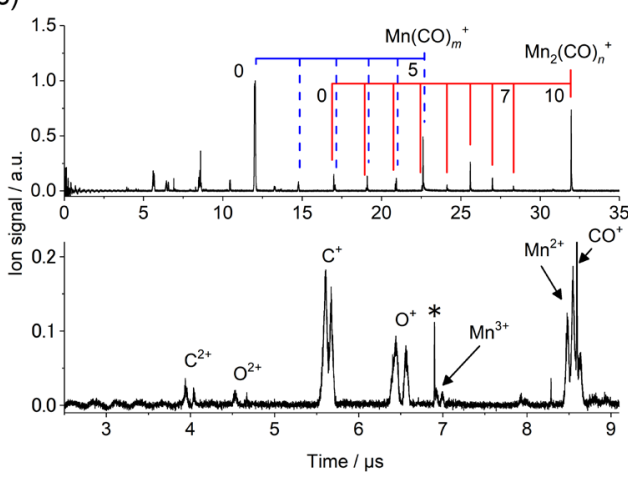

Fig. 1. Time-of-flight spectra of $\mathrm{Mn}_{2}(\mathrm{CO})_{10}$. Laser intensity was (a) $3.2 \times 10^{15}$, (b) $7.0 \times 10^{14}$, and (c) $9.7 \times 10^{13} \mathrm{~W} \mathrm{~cm}^{-2}$, respectively. The upper and lower panels show an entire and a magnified spectrum. The laser polarization was parallel to the ion flight axis. The asterisks indicate the ions originating from contaminated water and air. 


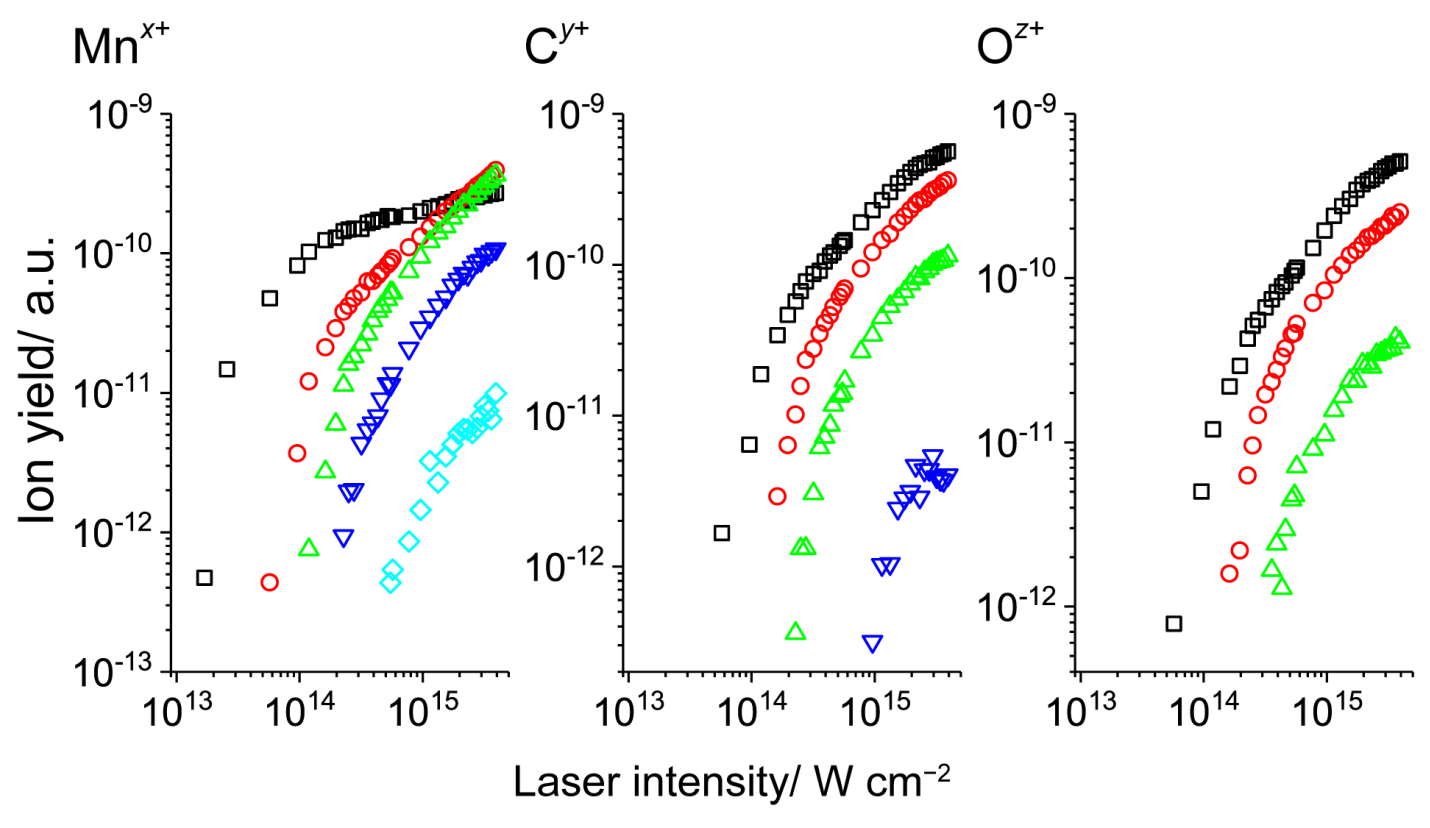

Fig. 2. The yields of atomic ions ejected from $\mathrm{Mn}_{2}(\mathrm{CO})_{10}$ as a function of laser intensity: left panel, $\mathrm{Mn}^{+}$(squares), $\mathrm{Mn}^{2+}$ (circles), $\mathrm{Mn}^{3+}$ (triangles), $\mathrm{Mn}^{4+}$ (inverted triangles), $\mathrm{Mn}^{5+}$ (diamonds); middle panel, $\mathrm{C}^{+}$(square), $\mathrm{C}^{2+}$ (circle), $\mathrm{C}^{3+}$ (triangle), $\mathrm{C}^{4+}$ (inverted triangles); right panel, $\mathrm{O}^{+}$(square), $\mathrm{O}^{2+}$ (circle), $\mathrm{O}^{3+}$ (triangle). The laser polarization was parallel $\left(\mathrm{O}^{+}\right.$, $\mathrm{O}^{2+}, \mathrm{O}^{3+}, \mathrm{C}^{3+}, \mathrm{C}^{4+}$, metal ions) or orthogonal $\left(\mathrm{C}^{+}, \mathrm{C}^{2+}\right)$ to the ion flight axis. Detector sensitivity was not corrected. 

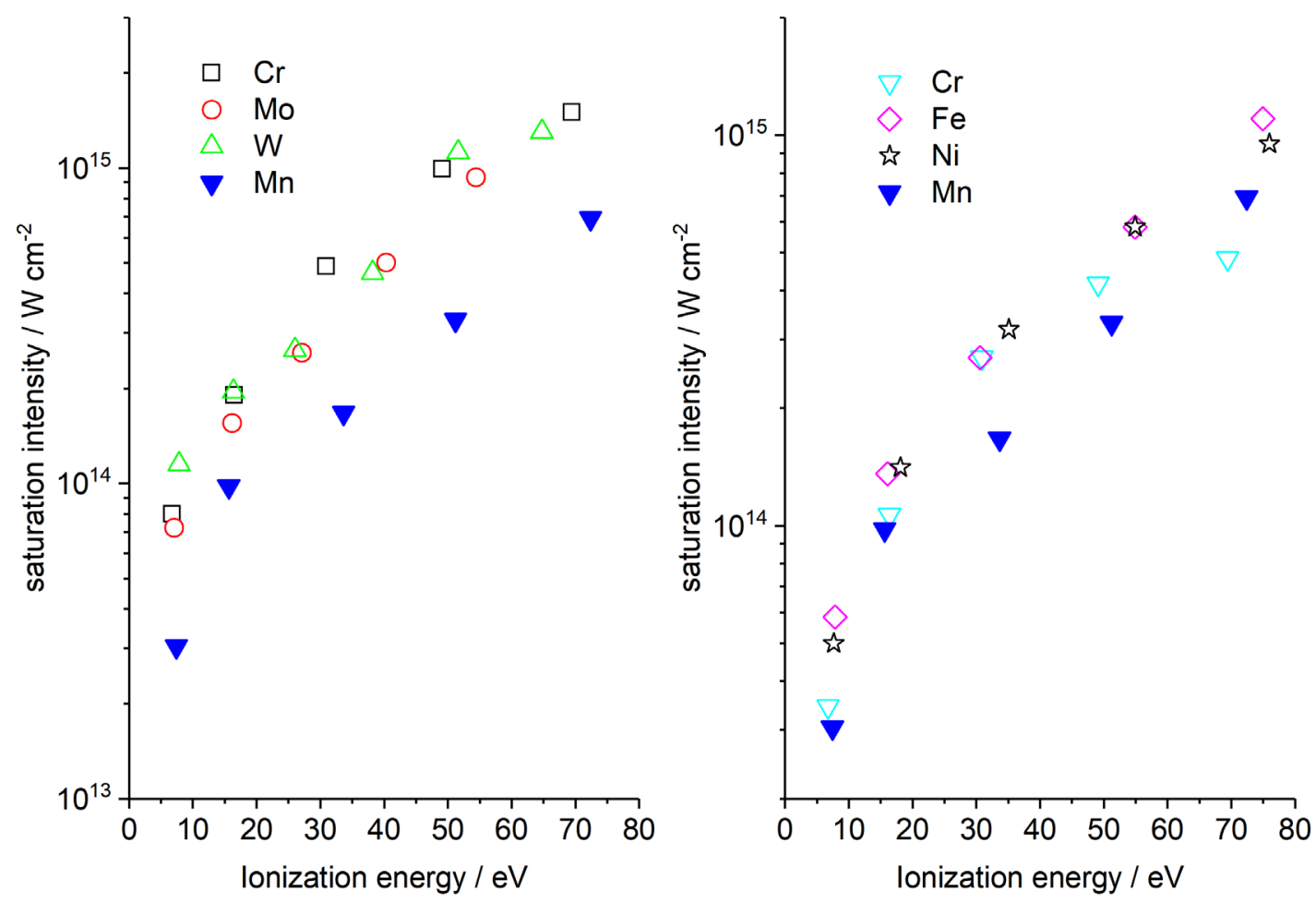

Fig. 3. The saturation intensity of meal ions as a function of the ionization energy of metal atoms. The saturation intensities of Mn ions (filled inverted triangles) ejected from $\mathrm{Mn}_{2}(\mathrm{CO})_{10}$ were compared with the metal ions emerged from (left) metal hexacarbonyls and (right) metallocenes. The data of $\mathrm{Cr}$ (open squares), Mo (open circles), W (open triangles) ions ejected from the corresponding metal hexacarbonyls were taken from Ref. [26]. The data of $\mathrm{Cr}$ (open inverted triangles), $\mathrm{Fe}$ (open diamonds), and $\mathrm{Ni}$ (open stars) ions ejected from the corresponding metallocenes were taken from Ref. [28]. Date of ionization energy are taken from Kramida, A., Ralchenko, Yu., Reader, J., and NIST ASD Team (2018). NIST Atomic Spectra Database (ver. 5.6.1), [Online]. Available: https://physics.nist.gov/asd [2019, June 24]. National Institute of Standards and Technology, Gaithersburg, MD. DOI: https://doi.org/10.18434/T4W30F 


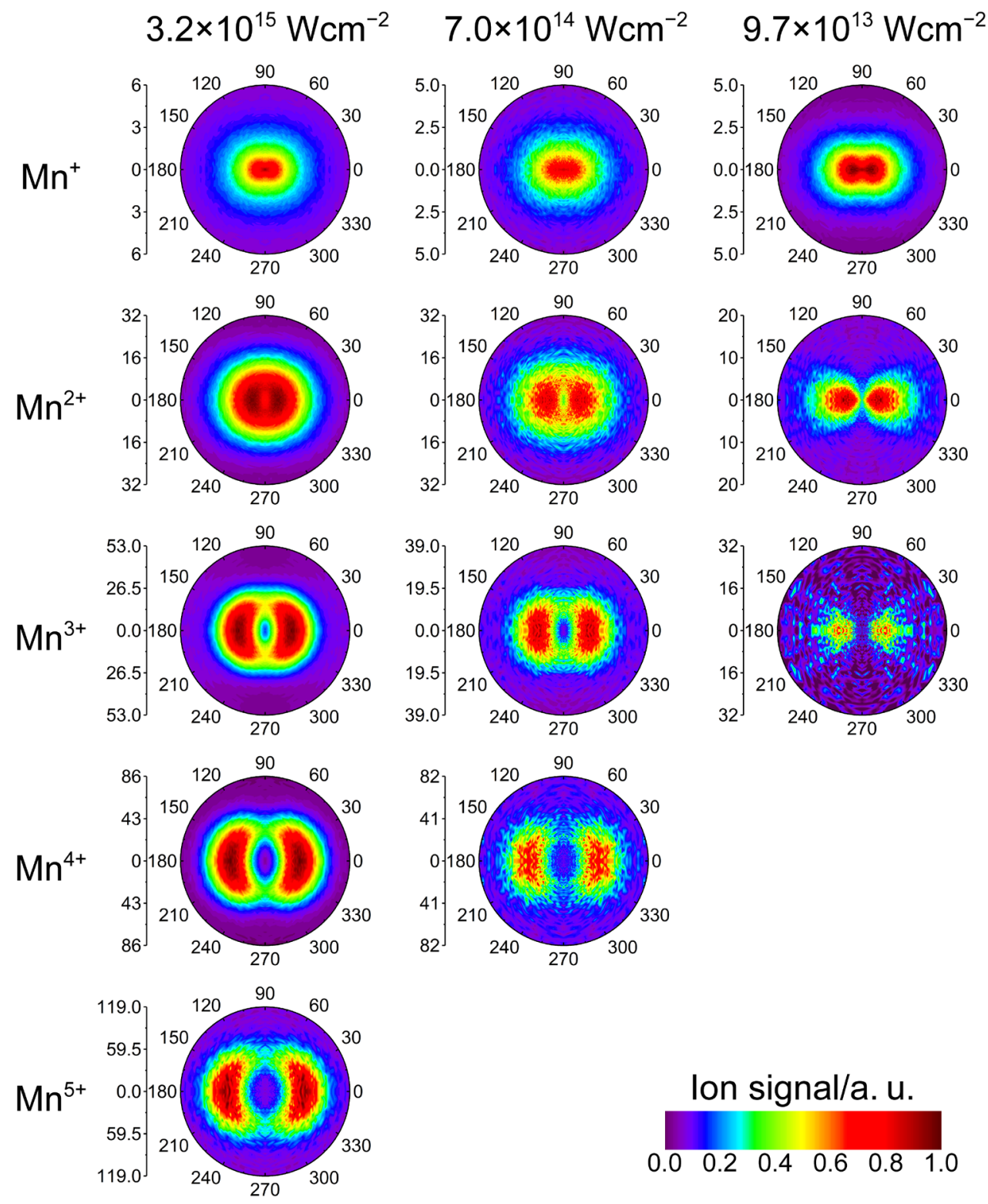

Fig. 4. Angular distribution of $\mathrm{Mn}^{x+}(x=1-5)$ ejected from $\mathrm{Mn}_{2}(\mathrm{CO})_{10}$. Laser intensity was $3.2 \times 10^{15}$ (left), $7.0 \times 10^{14}$ (middle), and $9.7 \times 10^{13} \mathrm{~W} \mathrm{~cm}^{-2}$ (right), respectively. The ion intensity in the polar plot is expressed by a linear color code, where the ion intensity was normalized at peak kinetic energy. The radius indicates kinetic energy in eV units. The maximum radius is fixed to 1.2 times larger than the maximum kinetic energy. Angle in the polar plot indicates the relative angle between the polarization plane of the laser fields and the ion flight axis to the detector. 

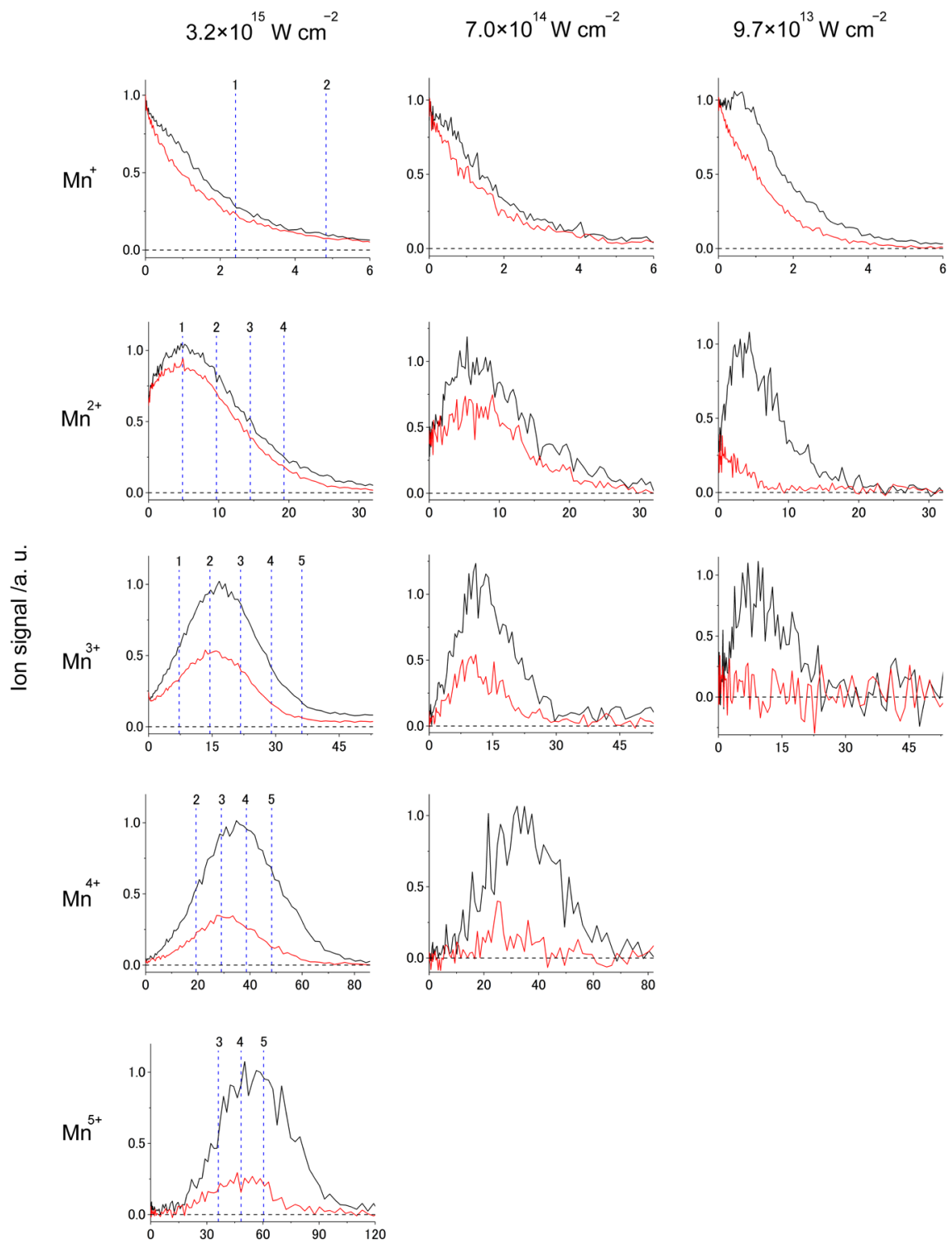

Kinetic energy / eV

Fig. 5. The kinetic energy spectra of $\mathrm{Mn}^{x+}(x=1-5)$ ejected from $\mathrm{Mn}_{2}(\mathrm{CO})_{10}$. The black and red lines indicate the data obtained under parallel $\left(\theta=0^{\circ}, 180^{\circ}\right)$ and orthogonal $\left(\theta=90^{\circ}\right.$, $270^{\circ}$ ) conditions, respectively. Laser intensity was $3.2 \times 10^{15}$ (left), $7.0 \times 10^{14}$ (middle), and $9.7 \times 10^{13} \mathrm{~W} \mathrm{~cm}^{-2}$ (right). The dashed line indicates the kinetic energy evaluated by assuming Coulomb repulsion with manganese ion with the charge number shown above the lines. Ion signal was normalized to unity at peak kinetic energy. The maximum value of horizontal axis is fixed to 1.2 times larger than the maximum kinetic energy measured at $3.2 \times 10^{15} \mathrm{~W} \mathrm{~cm}^{-2}$. 

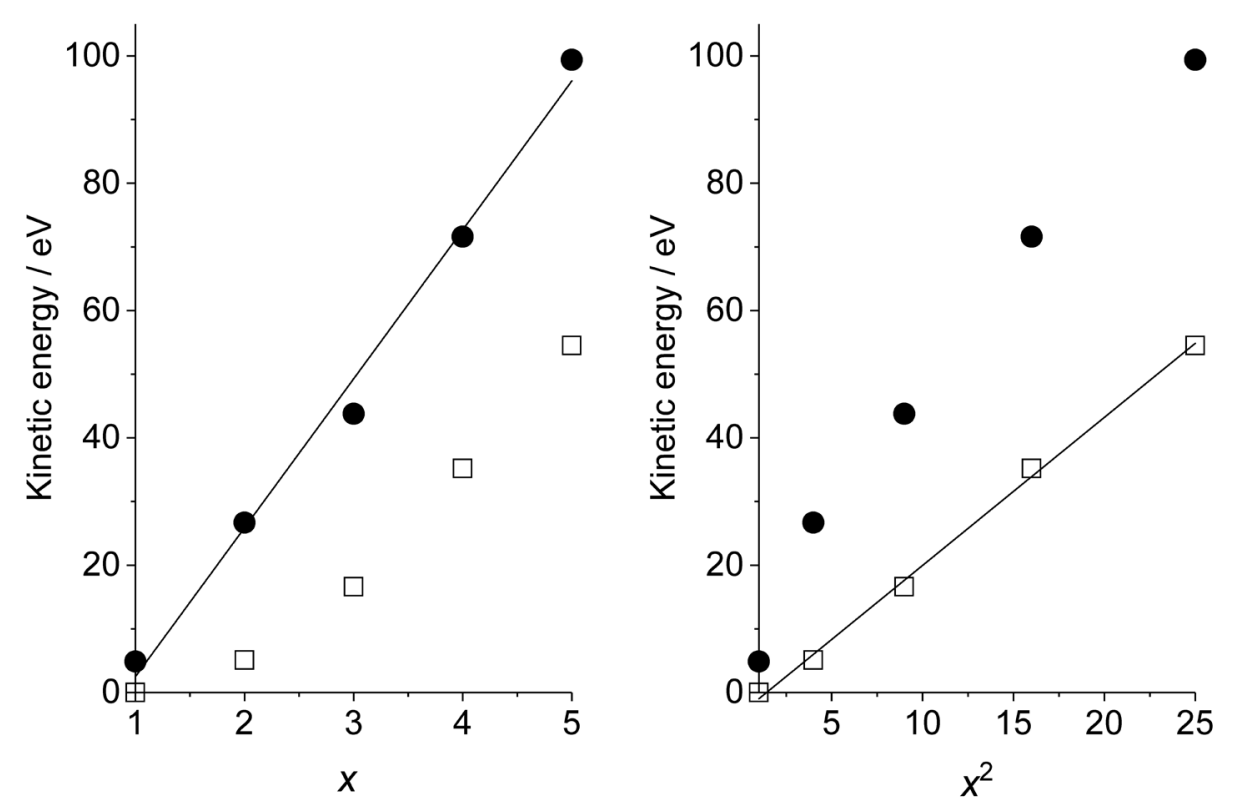

Fig. 6. The peak (open squares) and maximum (filled circles) kinetic energy of $\mathrm{Mn}^{x+}(x=$ $1-5)$ as a function of $x$ (left) or the square of $x$ (right). Laser intensity was $3.2 \times 10^{15} \mathrm{~W} \mathrm{~cm}^{-2}$. Linear lines are the results of least square fitting. 


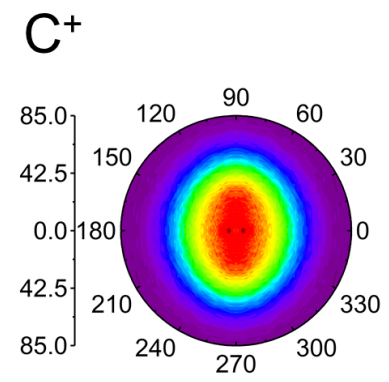

$\mathrm{C}^{2+}$
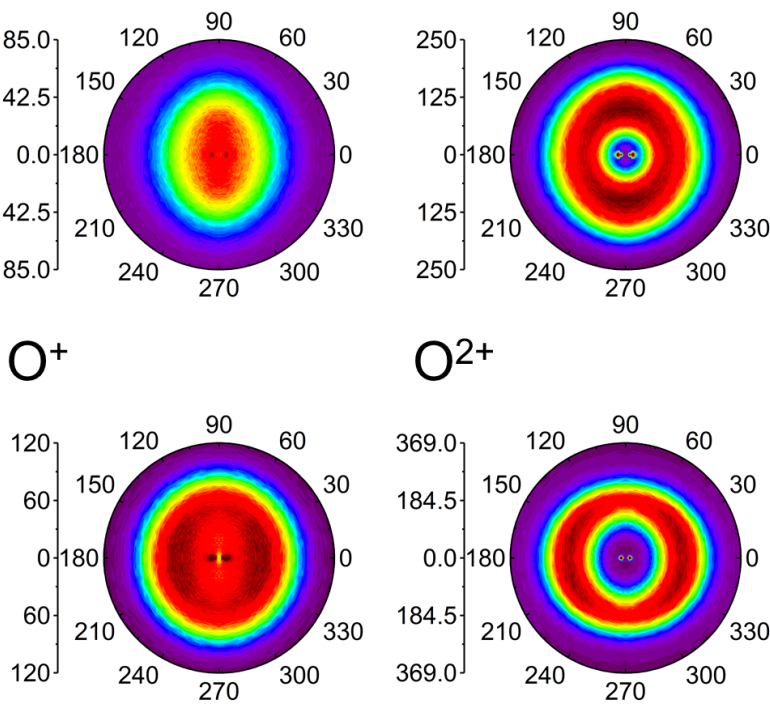

$\mathrm{C}^{3+}$

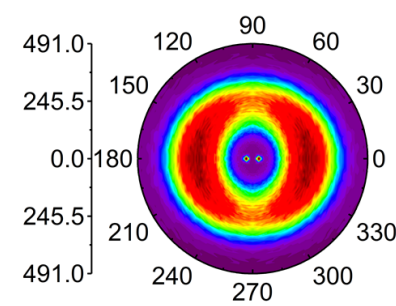

$\mathrm{O}^{3+}$
$\mathrm{C}^{4+}$
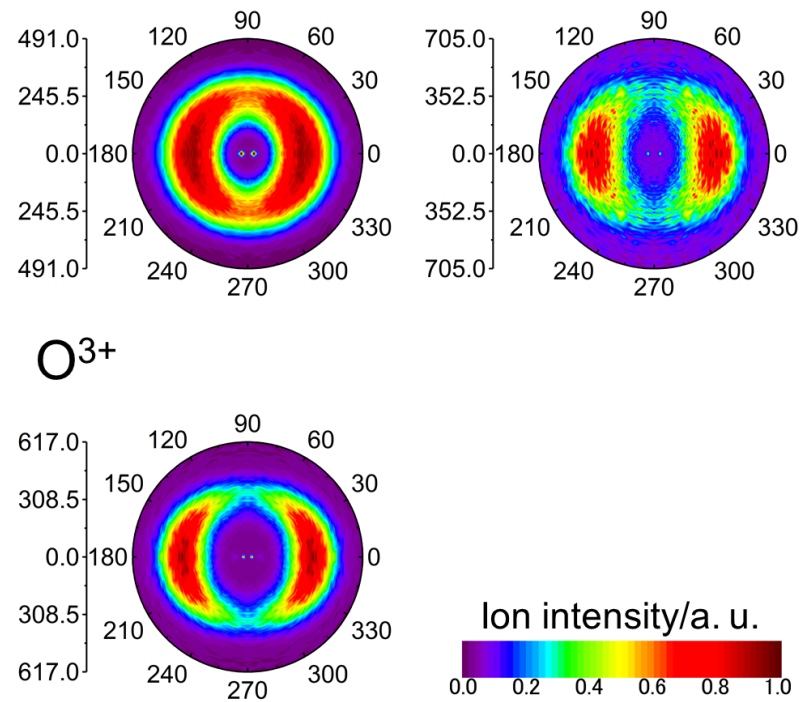

Ion intensity/a. u.

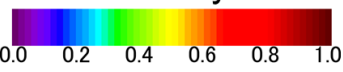

Fig. 7. Angular distribution of $\mathrm{C}^{y^{+}}(y=1-4)$, and $\mathrm{O}^{z+}(z=1-3)$ ejected from $\mathrm{Mn}_{2}(\mathrm{CO})_{10}$. Laser intensity was $3.2 \times 10^{15} \mathrm{~W} \mathrm{~cm}^{-2}$. The ion intensity in the polar plot is expressed by a linear color code. The radius indicates kinetic energy in $\mathrm{eV}$ units. The maximum radius is fixed to 1.2 times larger than the maximum kinetic energy. Angle in the polar plot indicates the relative angle between the polarization plane of the laser fields and the ion flight axis to the detector. Ion intensity was normalized to unity at peak kinetic energy. 


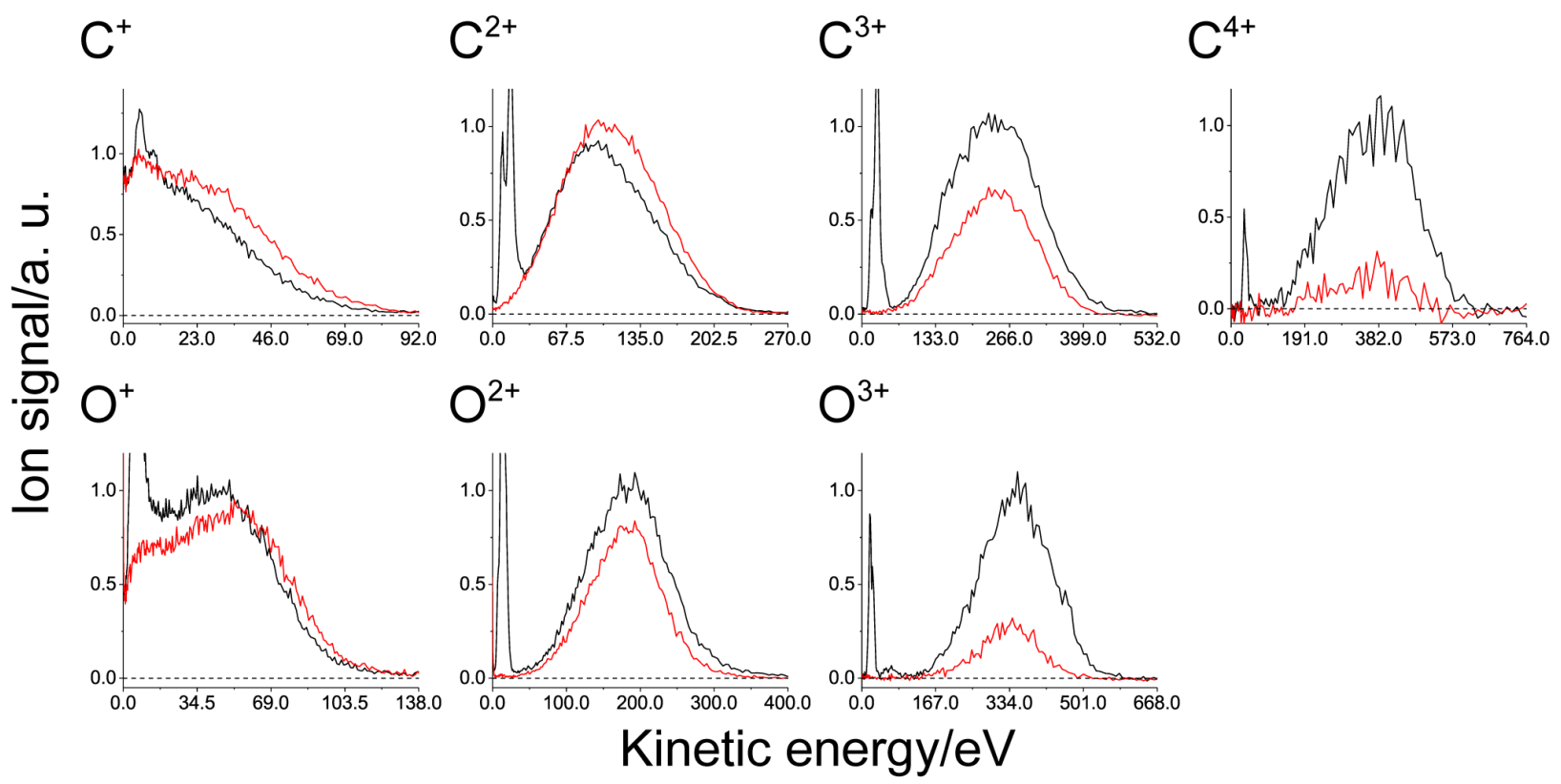

Fig. 8. The kinetic energy spectra of $\mathrm{C}^{y^{+}}(y=1-5)$ and $\mathrm{O}^{z+}(z=1-5)$ ejected from $\mathrm{Mn}_{2}(\mathrm{CO})_{10}$. The black and red lines indicate the data obtained under parallel $\left(\theta=0^{\circ}, 180^{\circ}\right)$ and orthogonal $\left(\theta=90^{\circ}, 270^{\circ}\right)$ conditions, respectively. Laser intensity was $3.2 \times 10^{15} \mathrm{~W} \mathrm{~cm}^{-2}$. Ion signal was normalized to unity at peak kinetic energy. The maximum value of horizontal axis is fixed to 1.2 times larger than the maximum kinetic energy. 


\section{Table 1}

Peak and maximum kinetic energies of manganese ions ejected from $\mathrm{Mn}_{2}(\mathrm{CO})_{10}$

\begin{tabular}{|c|c|c|c|c|c|c|}
\hline \multirow{3}{*}{ Ions } & \multicolumn{6}{|c|}{ Kinetic energy / eV } \\
\hline & \multicolumn{2}{|c|}{$3.2 \times 10^{15} \mathrm{~W} \mathrm{~cm}^{-2}$} & \multicolumn{2}{|c|}{$7.0 \times 10^{14} \mathrm{~W} \mathrm{~cm}^{-2}$} & \multicolumn{2}{|c|}{$9.7 \times 10^{13} \mathrm{~W} \mathrm{~cm}^{-2}$} \\
\hline & Peak $^{b}$ & Maximum $^{\mathrm{c}}$ & Peak $^{b}$ & Maximum $^{\mathrm{c}}$ & Peak $^{b}$ & Maximum $^{\mathrm{c}}$ \\
\hline $\mathrm{Mn}^{+}$ & $0(1.0)$ & 4.9 & $0(1.0)$ & 4.3 & $0.55(0.67)$ & 3.9 \\
\hline $\mathrm{Mn}^{2+}$ & $5.1(0.83)$ & 26.7 & $6.1(0.63)$ & 27.1 & $3.5(0.16)$ & 16.8 \\
\hline $\mathrm{Mn}^{3+}$ & $16.6(0.53)$ & 43.8 & $11.8(0.45)$ & 32.2 & $8.6(0)$ & 26.6 \\
\hline $\mathrm{Mn}^{4+}$ & $35.2(0.34)$ & 71.6 & $34.2(0.23)$ & 68.0 & - & - \\
\hline $\mathrm{Mn}^{5+}$ & $54.5(0.23)$ & 99.4 & - & - & - & - \\
\hline
\end{tabular}

a Laser polarization is parallel to the ion flight axis.

b Peak kinetic energy is defined as the energy at peak ion intensity. The extinction value, the ratio of the manganese ion intensity (peak value) measured under an orthogonal condition to that measured under a parallel, is shown in parentheses.

c Defined as an energy at $10 \%$ of the peak ion intensity. 
Table 2. Peak and maximum kinetic energies of oxygen and carbon ions ejected from $\mathrm{Mn}_{2}(\mathrm{CO})_{10}$ at $3.2 \times 10^{15} \mathrm{~W} \mathrm{~cm}^{-2}$ and from $\mathrm{Cr}(\mathrm{CO})_{6}$ at $1.4 \times 10^{15} \mathrm{~W} \mathrm{~cm}^{-2}$

\begin{tabular}{|c|c|c|c|c|}
\hline \multirow{3}{*}{ Ions } & \multicolumn{4}{|c|}{ Kinetic energy / eV } \\
\hline & \multicolumn{2}{|l|}{$\mathrm{Mn}_{2}(\mathrm{CO})_{10}$} & \multicolumn{2}{|c|}{$\mathrm{Cr}(\mathrm{CO}) 6^{\mathrm{a}}$} \\
\hline & Peak $^{b}$ & Maximum $^{\mathrm{c}}$ & Peak $^{\mathrm{b}}$ & Maximum $^{\mathrm{c}}$ \\
\hline $\mathrm{O}^{+\mathrm{d}}$ & $43.3(0.91)$ & 100 & $24.2(0.40)$ & 64.8 \\
\hline $\mathrm{O}^{2+\mathrm{d}}$ & $13.5(0), 186(0.77)$ & 308 & $124(0.47)$ & 201 \\
\hline $\mathrm{O}^{3+\mathrm{d}}$ & $19.5(0), 353(0.29)$ & 515 & $220(0.20)$ & 317 \\
\hline $\mathrm{C}^{+\mathrm{e}}$ & $5.25(0.77), 18.6(1.08)$ & 70.8 & $17.7(1.2)$ & 46.4 \\
\hline $\mathrm{C}^{2+\mathrm{e}}$ & $9.2(0), 17.0(0), 98.4(1.1)$ & 208 & $60.4(1.1)$ & 130 \\
\hline $\mathrm{C}^{3+\mathrm{d}}$ & $27.9(0), 239(0.63)$ & 409 & $151(0.44)$ & 248 \\
\hline $\mathrm{C}^{4+\mathrm{d}}$ & $34.0(0), 391(0.16)$ & 588 & - & - \\
\hline
\end{tabular}

a Data are taken from Ref. [26]

b Peak kinetic energy is defined as the energy at peak ion intensity. The extinction value, the ratio of the ion intensity (peak value) measured under a parallel condition to that measured under an orthogonal condition, is shown in parenthesis.

c Defined as an energy at $10 \%$ of the peak ion intensity.

$\mathrm{d}$ Laser polarization is parallel to the ion flight axis.

e Laser polarization is orthogonal to the ion flight axis. 


\section{References}

[1] L.J. Frasinski, K. Codling, P. Hatherly, J. Barr, I.N. Ross, W.T. Toner, Femtosecond dynamics of multielectron dissociative ionization by use of picosecond laser, Phys. Rev. Lett., 58 (1987) 2424-2427.

[2] J.H. Posthumus, The dynamics of small molecules in intense laser fields, Rep. Prog. Phys., 67 (2004) 623-665.

[3] N. Nakashima, S. Shimizu, T. Yatsuhashi, S. Sakabe, Y. Izawa, Large molecules in highintensity laser fields, J. Photochem. Photobiol. C, 1 (2000) 131-143.

[4] T. Yatsuhashi, N. Nakashima, Multiple ionization and Coulomb explosion of molecules, molecular complexes, clusters and solid surfaces, J. Photochem. Photobiol. C, 34 (2018) 5284.

[5] A. Hishikawa, A. Iwamae, K. Yamanouchi, Ultrafast deformation of the geometrical structure of CO2 induced in intense laser fields, Phys. Rev. Lett., 83 (1999) 1127-1130.

[6] C.S. Slater, S. Blake, M. Brouard, A. Lauer, C. Vallance, C.S. Bohun, L. Christensen, J.H. Nielsen, M.P. Johansson, H. Stapelfeldt, Coulomb-explosion imaging using a pixel-imaging mass-spectrometry camera, Phys. Rev. A, 91 (2015) 053424.

[7] H. Hasegawa, A. Hishikawa, K. Yamanouchi, Coincidence imaging of Coulomb explosion of CS2 in intense laser fields, Chem. Phys. Lett., 349 (2001) 57-63.

[8] M. Comstock, V. Senekerimyan, M. Dantus, Ultrafast laser induced molecular alignment and deformation: Experimental evidence from neutral molecules and from fragment ions, J. Phys. Chem. A, 107 (2003) 8271-8281.

[9] A. Matsuda, E.J. Takahashi, A. Hishikawa, Time-resolved laser Coulomb explosion imaging using few-cycle intense laser pulses: Application to exploding CS2 in highly charged states, J. Electron. Spectrosc. Relat. Phenom., 195 (2014) 327-331.

[10] B. Wales, E. Bisson, R. Karimi, S. Beaulieu, A. Ramadhan, M. Giguere, Z.J. Long, W.K. Liu, J.C. Kieffer, F. Legare, J. Sanderson, Coulomb imaging of the concerted and stepwise break up processes of OCS ions in intense femtosecond laser radiation, J. Electron. Spectrosc. Relat. Phenom., 195 (2014) 332-336.

[11] C.M. Tseng, M. Fushitani, A. Matsuda, A. Hishikawa, Coincidence momentum imaging of four- and three-body Coulomb explosion of formaldehyde in ultrashort intense laser fields, J. Electron. Spectrosc. Relat. Phenom., 228 (2018) 25-30. 
[12] T. Yatsuhashi, N. Mitsubayashi, M. Itsukashi, M. Kozaki, K. Okada, N. Nakashima, Persistence of iodines and deformation of molecular structure in highly charged diiodoacetylene: anisotropic carbon ion emission, ChemPhysChem, 12 (2011) 122-126. [13] M. Smits, C.A. de Lange, A. Stolow, D.M. Rayner, Absolute ionization rates of multielectron transition metal atoms in strong infrared laser fields, Phys. Rev. Lett., 93 (2004) 213003.

[14] M. Smits, C.A. de Lange, A. Stolow, D.M. Rayner, Dynamic polarization in the strongfield ionization of small metal clusters, Phys. Rev. Lett., 93 (2004) 203402.

[15] D.E. Blumling, S.G. Sayres, M.W. Ross, A.W. Castleman, Strong-field ionization of small niobium and tantalum clusters, Int. J. Mass Spectrom., 333 (2013) 55-58.

[16] M.W. Ross, A.W. Castleman, Extreme ionization leading to Coulomb explosion of small palladium and zirconium oxide clusters and reactivity with carbon monoxide, J. Phys. Chem. A, 117 (2013) 1030-1034.

[17] M.W. Ross, A.W. Castleman, Strong-field ionization and Coulomb explosion of small neodymium and europium oxide clusters, Chem. Phys. Lett., 565 (2013) 22-27.

[18] M.W. Ross, A.W. Castleman, Ultrafast ionization and subsequent coulomb explosion of zirconium oxide and tungsten carbide "superatomic" cluster species and comparison to group 10 metals, New J. Chem., 36 (2012) 2253-2259.

[19] M.W. Ross, A.W. Castleman, Ionization and Coulomb explosion of small group 10 transition metal oxide clusters in strong light fields, J. Chem. Phys., 137 (2012) 084307. [20] M.W. Ross, A.W. Castleman, Ionization and Coulomb explosion of small uranium oxide clusters, J. Phys. B, 45 (2012) 205102.

[21] S.G. Sayres, M.W. Ross, A.W. Castleman, Delocalized electronic behavior observed in transition metal oxide clusters under strong-field excitation, J. Chem. Phys., 135 (2011) 054312 .

[22] D.E. Blumling, S.G. Sayres, A.W. Castleman, Strong-field ionization and dissociation studies of small early transition metal oxide clusters, Int. J. Mass Spectrom., 300 (2011) 7480.

[23] M.W. Ross, A.W. Castleman, Femtosecond ionization and Coulomb explosion of small transition metal carbide clusters, Chem. Phys. Lett., 547 (2012) 13-20.

[24] D.E. Blumling, S.G. Sayres, A.W. Castleman, Strong-field ionization and dissociation studies on small early transition metal carbide clusters via time-of-flight mass spectrometry, J. Phys. Chem. A, 115 (2011) 5038-5043. 
[25] S.A. Trushin, W. Fuss, W.E. Schmid, Dissociative ionization at high laser intensities: importance of resonances and relaxation for fragmentation, J. Phys. B, 37 (2004) 3987-4011. [26] H. Tanaka, N. Nakashima, T. Yatsuhashi, Anisotropic Coulomb explosion of CO ligands in group 6 metal hexacarbonyls: $\mathrm{Cr}(\mathrm{CO})(6), \mathrm{Mo}(\mathrm{CO})(6), \mathrm{W}(\mathrm{CO})(6)$, J. Phys. Chem. A, 120 (2016) 6917-6928.

[27] T. Yatsuhashi, E. Murakami, N. Nakashima, Fez+ $(z=1-6)$ generation from ferrocene, Phys. Chem. Chem. Phys., 13 (2011) 4234-4238.

[28] E. Murakami, R. Mizoguchi, Y. Yoshida, A. Kitashoji, N. Nakashima, T. Yatsuhashi, Multiple strong field ionization of metallocenes: Applicability of ADK rates to the production of multiply charged transition metal (Cr, Fe, Ni, Ru, Os) cations, J. Photochem. Photobiol., A, 369 (2019) 16-24.

[29] P. Badani, S. Das, P. Sharma, R.K. Vatsa, Mass spectrometric and charge density studies of organometallic clusters photoionized by gigawatt laser pulses, Mass Spectrom. Rev., 36 (2017) 188-212.

[30] P.M. Badani, S. Das, P. Sharma, R.K. Vatsa, Generation of multiply charged tin and carbon ions in low intensity Coulomb explosion of tetramethyl tin clusters: Role of screening effects, Int. J. Mass Spectrom., 358 (2014) 36-42.

[31] S.R. Krishnan, R. Gopal, R. Rajeev, J. Jha, V. Sharma, M. Mudrich, R. Moshammer, M. Krishnamurthy, Photoionization of clusters in intense few-cycle near infrared femtosecond pulses, Phys. Chem. Chem. Phys., 16 (2014) 8721-8730.

[32] U. Saalmann, C. Siedschlag, J.M. Rost, Mechanisms of cluster ionization in strong laser pulses, J. Phys. B, 39 (2006) R39-R77.

[33] T. Fennel, K.H. Meiwes-Broer, J. Tiggesbaumker, P.G. Reinhard, P.M. Dinh, E. Suraud, Laser-driven nonlinear cluster dynamics, Rev. Mod. Phys., 82 (2010) 1793-1842.

[34] N. Mitsubayashi, T. Yatsuhashi, H. Tanaka, S. Furukawa, M. Kozaki, K. Okada, N. Nakashima, Anisotropic Coulomb explosion of acetylene and diacetylene derivatives, Int. J. Mass Spectrom., 403 (2016) 43-52.

[35] S.M. Hankin, D.M. Villeneuve, P.B. Corkum, D.M. Rayner, Intense-field laser ionization rates in atoms and molecules, Phys. Rev. A, 64 (2001) 013405.

[36] S.M. Hankin, D.M. Villeneuve, P.B. Corkum, D.M. Rayner, Nonlinear ionization of organic molecules in high intensity laser fields, Phys. Rev. Lett., 84 (2000) 5082-5085.

[37] T. Yatsuhashi, N. Nakashima, Dissociation and multiply charged silicon ejection in high abundance from hexamethyldisilane, J. Phys. Chem. A, 114 (2010) 11890-11895. 
[38] T. Yatsuhashi, N. Nakashima, Formation and fragmentation of quadruply charged molecular ions by intense femtosecond laser pulses, J. Phys. Chem. A, 114 (2010) 7445-7452. [39] T. Yatsuhashi, K. Toyota, N. Mitsubayashi, M. Kozaki, K. Okada, N. Nakashima, Intact four-atom organic tetracation stabilized by charge localization in the gas phase, ChemPhysChem, 17 (2016) 2977-2981.

[40] A. Kitashoji, T. Yatsuhashi, Definitive production of intact organic pentacation radical: Octafluoronaphthalene ionized in intense femtosecond laser fields, Chem. Phys., 526 (2019) 110465.

[41] A. Kitashoji, A. Fujihara, T. Yoshikawa, T. Yatsuhashi, The Smallest Aromatic Tetracation Produced in Gas Phase by Intense Femtosecond Laser Pulses, Chem. Lett., https://doi.org/10.1246/cl.190667.

[42] J. Opitz, D. Bruch, Multiphoton and Electron-Impact Ionization of Manganese Decacarbonyl Mn2(Co)10 at 351-Nm, 248-Nm and 193-Nm - Wavelength Dependent Competition between Ionization and Dissociation, Int. J. Mass Spectrom. Ion Processes, 124 (1993) 157-169.

[43] S.K. Kim, S. Pedersen, A.H. Zewail, Femtochemistry of organometallics: dynamics of metal-metal and metal-ligand bond cleavage in $\mathrm{M}(2)(\mathrm{CO})(10)$, Chem. Phys. Lett., 233 (1995) 500-508.

[44] D.S. Levine, M. Head-Gordon, Energy decomposition analysis of single bonds within Kohn-Sham density functional theory, Proc. Natl. Acad. Sci., 114 (2017) 12649-12656.

[45] L.J. Frasinski, K. Codling, P.A. Hatherly, Covariance mapping: a correlation method applied to multiphoton multiple ionization, Science, 246 (1989) 1029-1031.

[46] A. Almenningen, G.G. Jacobsen, H.M. Seip, On Molecular Structure of Dimanganese Decacarbonyl Mn2(CO)10, Acta Chem. Scand., 23 (1969) 685-686.

[47] G.N. Gibson, M. Li, C. Guo, J.P. Nibarger, Direct evidence of the generality of chargeasymmetric dissociation of molecular iodine ionized by strong laser fields, Phys. Rev. A, 58 (1998) 4723-4727.

[48] T. Zuo, A.D. Bandrauk, Charge-resonance-enhanced ionization of diatomic molecular ions by intense lasers, Phys. Rev. A, 52 (1995) R2511-R2514.

[49] T. Seideman, M.Y. Ivanov, P.B. Corkum, Role of Electron Localization in Intense-Field Molecular Ionization, Phys. Rev. Lett., 75 (1995) 2819-2822.

[50] E. Constant, H. Stapelfeldt, P.B. Corkum, Observation of enhanced ionization of molecular ions in intense laser fields, Phys. Rev. Lett., 76 (1996) 4140-4143. 
[51] C. Cornaggia, M. Schmidt, D. Normand, Laser-induced nuclear motions in the Coulomb explosion of C2H2+ ions, Phys. Rev. A, 51 (1995) 1431-1437.

[52] M. Martin, B. Rees, A. Mitschler, Bonding in a Binuclear Metal Carbonyl: Experimental Charge Density in Mn2(CO)10, Acta Crystallogr B, 38 (1982) 6-15. 